\title{
Singular Perturbation Method for Boundary Value and Optimal Problems to Power Factor Correction Converter Application
}

\author{
G. KISHOR BABU \\ Department of Electrical and Electronics Engineering \\ Gudlavalleru Engineering College \\ Gudlavaller \\ INDIA.
}

\begin{abstract}
A linear discrete stable control system is gpnsidered. The Power Factor Correction (PFC) small parameters inductor and capacitor its computes stiffness and to include switching ripple effects. As an alternative a Singular Perturbation Method (SPM) is presented Boundary Value Problem (BVP) and Optimal Problem. It is applied to two state switching power converters to provide rigorous justification of the time scale separation. It is modeled as a one parameter singularly perturbed system. SPM consists of an outer series solution and one boundary layer correction (BLC) solution. A boundary layer correction is required to recover the initial conditions lost in the process of degeneration and to improve the solution. SPM is carried out up to second-order approximate solution for the PFC converter model for BVP and optimal control problems. The results are compared with the exact solution (between with and without parameters). The results substantiate the application.
\end{abstract}

Key-Words: - Power Factor Correction; Singular Perturbation Method; Stability; Boundary Value Problem; Optimal Control Problem.

Received: August 20, 2019. Revised: December 15, 2019. Accepted: February 4, 2020. Published: March 31, 2020.

\section{Introduction}

The singularly perturbed systems are illconditioned systems with computational stiffness. Hence exact solution of these systems requires special numerical methods to overcome this stiffness. The SPM removes the stiffness of the system, reduces the order of the system and satisfies all the specified boundary conditions thereby giving a solution very close to the exact solution. The singularly perturbed systems are time-scale systems. A two-time scale system results in one parameter singularly perturbed system. A three-time scale system results in a two parameter singularly perturbed system. Similarly a Multi Time Scale (MTS) system results in $\mathrm{n}$ parameter singularly perturbed system. MTS systems are highly stiff exhibiting chaotic behavior with butterfly phenomenon. Obviously these systems need an alternative. The alternative is SPM. The singular perturbation theory is well developed for continuoustime control systems [1-10] compared to discretetime control systems [11-20]. Chaos associated with multiple time-scales exhibiting butterfly phenomenon [21] creates hurdles for finding the solution.

Conventional wisdom in power electronics is that in DC-DC converters and many other applications, inductor currents are "fast" state variables, while capacitor voltages are "slow" state variables. Often, this is used as justification for a particular design methodology or control scheme as singular perturbation method. As power conversion densities increase, switching frequencies increase, control bandwidths increase, and components are miniaturized, a designer should wonder whether the conventional wisdom is still valid. Frequently, controllers for DC-DC converters use two loops: an inner current loop and an outer voltage loop. The current loop can take many forms. If there is a separation in timescales between the current dynamics and voltage dynamics, the two loops can be designed independently.

While timescale separation, removes the stiffness of the system and reduces the order of the system are important for many DC-DC converters, power factor correction converters require singular perturbation method for proper operation. The objective of a PFC converter is to force an inductor current to follow the input voltage wave shape (normally a rectified sinusoid), while the output capacitor voltage is as close to dc as possible [29]. The typical solution is to use a large output capacitor to smooth out the power fluctuations from the input. Hence, reduce error between with separation and without separation by SPM.

Here a singular perturbation theory for DCDC Converters and application to PFC Converters 
with two time scales is considered as a case study. It is modeled as a one parameter SPS then IVP, BVP and optimal problems are studied using the SPM extended up to second-order approximation

Singular perturbation theory [28] is a tool for formally partitioning a dynamic system into slow and fast variables. The two timescales differ in scale by a small parametere. The fast variables, denoted here as $\mathrm{x} 1$, are related to the slow variables, denoted as $\mathrm{x} 0$, by an integral manifold (an algebraic relation) plus a small dynamic error parameter $\varepsilon$.

\section{Singular Perturbation Method}

\section{Discrete Multi-Parameter Problem}

The multi-parameter discrete control systems are being studied extensively. From control view here we present the Discrete Multi-Parameter Singular Perturbation Method (DMPSPM) in state space form. Consider the linear, singularly perturbed multiparameter discrete control system. This can be represented as

$$
\begin{gathered}
\mathrm{xj}(\mathrm{k}+1)=\mathrm{A}\left[\mu 0 \ldots \mu \mathrm{j} \mathrm{x}_{\mathrm{j}}(\mathrm{k})\right]+\mathrm{B} \mathrm{u}(\mathrm{k}) \\
\mathrm{xj}(\mathrm{k}+1)=\mathrm{A}\left[\varepsilon 0 \ldots \varepsilon j \mathrm{x}_{\mathrm{j}}(\mathrm{k})\right]+\mathrm{B} \mathrm{u}(\mathrm{k}) \quad(1 \mathrm{a}) \\
\mathrm{x}_{\mathrm{j}}(\mathrm{k}=0)=\mathrm{x}_{\mathrm{j}}(0), \mathrm{j}=0,1, \ldots, \mathrm{n} . \\
\text { where } \mathrm{A}=\left[\begin{array}{cccc}
\mathrm{A}_{11} & \mathrm{~A}_{12} & \ldots & \mathrm{A}_{1 \mathrm{~m}} \\
\mathrm{~A}_{21} & \mathrm{~A}_{22} & \ldots & \mathrm{A}_{2 \mathrm{~m}} \\
\vdots & \vdots & \vdots & \vdots \\
\mathrm{A}_{\mathrm{m} 1} & \mathrm{~A}_{\mathrm{m} 2} & \ldots & \mathrm{A}_{\mathrm{mm}}
\end{array}\right], \mathrm{B}=\left[\begin{array}{c}
\mathrm{B}_{1} \\
\mathrm{~B}_{2} \\
\vdots \\
\mathrm{B}_{\mathrm{m}}
\end{array}\right]
\end{gathered}
$$

and state vector $x_{j-1}(k) \in R^{n_{j}}, j=1,2, \ldots, m ; m$ $=\mathrm{n}+1$. Aij and $\mathrm{Bi}$ are matrices of suitable dimensionality. The control vector free of the small parameters is $\mathrm{u}(\mathrm{k}) \in \mathrm{R}^{\mathrm{r}}$. Redefined the parameters as $\varepsilon_{1}=\mu_{1}$ and $\varepsilon_{j}=\frac{\mu_{j}}{\mu_{j-1}}, j=2, \ldots, n$. The parameter $\varepsilon_{0}=\mu_{0}, \varepsilon_{1}$ is not a small parameter and is introduced to facilitate the presentation of the multiparameter problem. The initial conditions of the system (1b) are

$$
x_{j}(k=0)=x_{j}(0), j=0,1, \ldots, n .
$$

The $\left(\mathrm{n}_{1}+\mathrm{n}_{2}+\ldots+\mathrm{n}_{\mathrm{m}}\right)$ order discrete TPBVP represented by (1) is said to be in singularly perturbed form based on the degenerate TPBVP

$$
\begin{gathered}
{\left[\begin{array}{c}
\mathrm{x}_{0}^{0 \ldots 0}(\mathrm{k}+1) \\
\mathrm{x}_{\mathrm{j}}^{0 \ldots 0}(\mathrm{k}+1)
\end{array}\right]=\mathrm{A}\left[\begin{array}{c}
\mathrm{x}_{0}^{0 \ldots 0}(\mathrm{k}) \\
0
\end{array}\right]+\mathrm{Bu}(\mathrm{k}),} \\
\mathrm{j}=1,2, \ldots, \mathrm{n} .
\end{gathered}
$$

obtained by suppressing the small parameters $\varepsilon_{1}, \varepsilon_{2}, \ldots, \varepsilon_{n}$ in (2a) is of order $n 1$ and can satisfy the boundary conditions of slow modes only, resulting in

$$
\begin{aligned}
x_{0}^{00 \ldots 0}(k=0) & =x_{0}(0) \text { and } x_{j}^{00 \ldots 0}(k=0) \neq x_{j}(0), \\
j & =1,2, \ldots, n .
\end{aligned}
$$

The $\left(\mathrm{n}_{2}+\ldots+\mathrm{n}_{\mathrm{m}}\right)$ initial condition missing in the process of degeneration are restored by the following singular perturbation method.

\section{Singular Perturbation Method (SPM) \\ 1. Boundary value problems (BVP)}

\section{(a). Outer solution}

Asymptotic expansions for the outer solution are expressed in terms of the small parameters as

$$
\begin{gathered}
\left\{\mathrm{x}_{\mathrm{v}, \mathrm{o}}(\mathrm{k})\right\}=\sum_{\mathrm{i}, \mathrm{j}, \ldots, \mathrm{r} \geq 0}^{\mathrm{q}}\left[\mathrm{x}_{\mathrm{v}}^{\mathrm{ij} \ldots \mathrm{r}}(\mathrm{k})\right] \varepsilon_{1}^{\mathrm{i}} \varepsilon_{2}^{\mathrm{j}} \ldots \varepsilon_{\mathrm{n}}^{\mathrm{r}}, \\
\mathrm{v}=0,1, \ldots, \mathrm{n} .
\end{gathered}
$$

for qth order of approximation. By substituting (3) in (1b) and equating like powers of the small parameter a set of equations may be obtained. (2a) is the resulting zero-order equation. We can get equations may be obtained for $\mathrm{n} \geq 3$.

\section{(b). Boundary layer correction (BLC) solutions}

In order to get back the boundary conditions lost due to degeneration, to supply the required boundary conditions to solve the outer and BLC equations and to get a distinctive solution, the following transformations need to be applied for the $\mathrm{n}$ boundary layer corrections.

Transformations for BLC:

$\mathrm{x}_{0 \text { ci }}(\mathrm{k})=\mathrm{x}_{0}(\mathrm{k}) /\left(\varepsilon_{1} \ldots \varepsilon_{\mathrm{i}}\right)^{\mathrm{k}+1}, \mathrm{i}=1,2 \ldots, \mathrm{n}$;

$\mathrm{x}_{1 \mathrm{c} 1}(\mathrm{k})=\mathrm{x}_{1}(\mathrm{k}) /\left(\varepsilon_{1}\right)^{\mathrm{k}}$

$\mathrm{x}_{1 \text { ci }}(\mathrm{k})=\mathrm{x}_{1}(\mathrm{k}) /\left(\varepsilon_{1}^{\mathrm{k}}\left(\varepsilon_{2} \ldots \varepsilon_{\mathrm{i}}\right)^{\mathrm{k}+1}\right), \mathrm{i}=2,3, \ldots, \mathrm{n}$.

$\mathrm{x}_{2 \mathrm{ci}}(\mathrm{k})=\mathrm{x}_{2}(\mathrm{k}) /\left(\varepsilon_{1} \ldots \varepsilon_{\mathrm{i}}\right)^{\mathrm{k}}, \mathrm{i}=1,2$;

$\mathrm{x}_{2 \mathrm{ci}}(\mathrm{k})=\mathrm{x}_{2}(\mathrm{k}) /\left(\left(\varepsilon_{1} \varepsilon_{2}\right)^{\mathrm{k}}\left(\varepsilon_{3} \ldots \varepsilon_{\mathrm{i}}\right)^{\mathrm{k}+1}\right), \mathrm{i}=3, \ldots, \mathrm{n}$;

$$
\mathrm{x}_{\mathrm{nci}}(\mathrm{k})=\mathrm{x}_{\mathrm{n}}(\mathrm{k}) /\left(\varepsilon_{1} \ldots \varepsilon_{\mathrm{i}}\right)^{\mathrm{k}}, \mathrm{i}=1,2, \ldots, \mathrm{n} .
$$

Here suffix $\mathrm{c}$ refers to initial boundary layer correction.

BLC Equations:

BLC equations may be obtained by seeking asymptotic expansions for $\mathrm{n}$ initial BLC as

$$
\begin{aligned}
\left\{\mathrm{x}_{\mathrm{vcs}}(\mathrm{k})\right\}=\sum_{\mathrm{ij} \ldots \mathrm{r} \geq 0}^{\mathrm{q}}\left\{\mathrm{x}_{\mathrm{vcs}}^{\mathrm{ij} \ldots \mathrm{r}}(\mathrm{k})\right\} \varepsilon_{1}^{\mathrm{i}} \varepsilon_{2}^{\mathrm{j}} \ldots \varepsilon_{\mathrm{n}}^{\mathrm{r}} ; \\
\mathrm{v}=0,1, \ldots \mathrm{n} . \mathrm{s}=1,2, \ldots, \mathrm{n} .
\end{aligned}
$$

for qth order of approximation. By substituting (5) in (4) and collecting the coefficients of like powers of the small parameters $\varepsilon_{1}, \varepsilon_{2}, \ldots, \varepsilon_{n}$; a set of subsystems for BLC may be obtained.

\section{(c). Total series solution (TSS)}

For a desired order of approximation q, the total series solution of states $\mathrm{x}(\mathrm{k})$ may be obtained from outer and BLC solutions as 


$$
\begin{aligned}
& \mathrm{x}_{0}^{\mathrm{q}}(\mathrm{k}) \\
& =\sum_{\mathrm{q}}^{\mathrm{q}}\left\{\mathrm{x}_{0}^{\mathrm{ij} \ldots \mathrm{r}}(\mathrm{k})\right\} \varepsilon_{1}^{\mathrm{i}} \varepsilon_{2}^{\mathrm{j}} \ldots \varepsilon_{\mathrm{n}}^{\mathrm{r}} \\
& +\sum_{\mathrm{s}=1}^{\mathrm{r}}\left(\varepsilon_{1} \ldots \varepsilon_{\mathrm{s}}\right)^{\mathrm{k}+1} \sum_{\mathrm{i}, \mathrm{j}, \ldots, \mathrm{r} \geq 0}^{\mathrm{q}}\left\{\mathrm{x}_{0 \mathrm{cs}}^{\mathrm{ij} \ldots \mathrm{r}}(\mathrm{k})\right\} \varepsilon_{1}^{\mathrm{i}} \varepsilon_{2}^{\mathrm{j}} \ldots \varepsilon_{\mathrm{n}}^{\mathrm{r}}
\end{aligned}
$$$$
\begin{aligned}
& \mathrm{x}_{\mathrm{f}}^{\mathrm{q}}(\mathrm{k}) \\
& =\sum_{\mathrm{i}, \mathrm{j}, \ldots, \mathrm{r} \geq 0}^{\mathrm{q}}\left\{\mathrm{x}_{\mathrm{f}}^{\mathrm{ij} \ldots \mathrm{r}}(\mathrm{k})\right\} \varepsilon_{1}^{\mathrm{i}} \varepsilon_{2}^{\mathrm{j}} \ldots \varepsilon_{\mathrm{n}}^{\mathrm{r}} \\
& +\sum_{\mathrm{s}=1}^{\mathrm{f}}\left(\varepsilon_{1} \ldots \varepsilon_{\mathrm{s}}\right)^{\mathrm{k}} \sum_{\mathrm{i}, \mathrm{j}, \ldots, \mathrm{r} \geq 0}^{\mathrm{q}}\left\{\mathrm{x}_{\mathrm{fcs}}^{\mathrm{ij} \ldots \mathrm{r}}(\mathrm{k})\right\} \varepsilon_{1}^{\mathrm{i}} \varepsilon_{2}^{\mathrm{j}} \ldots \varepsilon_{\mathrm{n}}^{\mathrm{r}} \\
& +\sum_{\mathrm{s}=\mathrm{f}+1}^{\mathrm{n}}\left(\varepsilon_{1} \ldots \varepsilon_{\mathrm{f}}\right)^{\mathrm{k}}\left(\varepsilon_{\mathrm{f}+1} \ldots \varepsilon_{\mathrm{s}}\right)^{\mathrm{k}+1}
\end{aligned}
$$$$
* \sum_{\mathrm{i}, \mathrm{j}, \ldots, \mathrm{r} \geq 0}^{\mathrm{q}}\left\{\mathrm{x}_{\mathrm{fcs}}^{\mathrm{ij} \ldots \mathrm{r}}(\mathrm{k})\right\} \varepsilon_{1}^{\mathrm{i}} \varepsilon_{2}^{\mathrm{j}} \ldots \varepsilon_{\mathrm{n}}^{\mathrm{r}} \quad \mathrm{f}=1,2, \ldots, \mathrm{n} .
$$

Here terms with negative power for singular perturbation parameters $\varepsilon_{\mathrm{i}}$ are defined to be zero, if any.

\section{(d). Boundary conditions}

The boundary conditions to solve outer equations $(2 \mathrm{a}, 3)$ and BLC equation are to be provided in advance. These are determined uniquely from the fact that the total series solution (6) should satisfy the specified boundary conditions (1c). Consequently the following boundary conditions result [18-20].

\section{(e). Algorithm}

The algorithm is similar to other SPM [20]. First start with zero-order solution to improve the degenerate solution. Here Outer and BLC solutions to be found using outer and BLC equations and conditions $(5,6)$. Then added according to TSS to get the zero-order solution. Similar procedure to be followed for first and higher order approximate solutions for further improvement.

\section{Optimal control problems}

\section{i. Problem Statement}

Consider the linear, time-invariant, completely controllable singularly perturbed multi-parameter discrete control system (1). The performance index to be minimized is

$\mathrm{J}=1 / 2 \sum_{\mathrm{k}=0}^{\mathrm{N}-1}\left[\mathrm{w}^{\prime}(\mathrm{k}) \operatorname{Dw}(\mathrm{k})+\mathrm{u}^{\prime}(\mathrm{k}) \mathrm{Ru}(\mathrm{k})\right]$

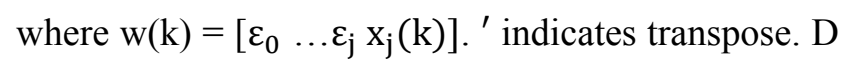
is a real positive-semidefinite symmetric matrix of order $(\mathrm{n} 1+\mathrm{n} 2+\ldots+\mathrm{nm}) \times(\mathrm{n} 1+\mathrm{n} 2+\ldots+\mathrm{nm}) . \mathrm{R}$ is real positive-definite symmetric matrix of order $(\mathrm{r} x$ $\mathrm{r}$ ) and $\mathrm{N}$ is a fixed integer indicating the terminal (final) time. Here note that the states are incorporated in an appropriate manner to bring the resulting TPBVP into singularly perturbed form. The Hamiltonian of the problem is

$$
\begin{aligned}
H(k)=\frac{1}{2} & w^{\prime}(k) D w(k)+\frac{1}{2} u^{\prime}(k) R u(k) \\
& +p^{\prime}(k+1)[A w(k)+B u(k)]
\end{aligned}
$$

where the co-state vector $\mathrm{p}(\mathrm{k})=\left[\varepsilon_{0} \ldots \varepsilon_{\mathrm{j}} \mathrm{p}_{\mathrm{j}}(\mathrm{k})\right]$

Using the results of digital optimal control theory [22-25]

$$
\begin{aligned}
& \partial \mathrm{H}(\mathrm{k}) /\left(\partial \varepsilon_{0} \ldots \varepsilon_{\mathrm{j}} \mathrm{p}_{\mathrm{j}}(\mathrm{k}+1)=\mathrm{x}_{\mathrm{j}}(\mathrm{k}+1)\right. \\
& \frac{\partial \mathrm{H}(\mathrm{k})}{\partial \mathrm{x}_{\mathrm{j}}(\mathrm{k})}=\varepsilon_{0} \ldots \varepsilon_{\mathrm{j}} \mathrm{p}_{\mathrm{j}}(\mathrm{k}) \\
& \frac{\partial \mathrm{H}(\mathrm{k})}{\partial \mathrm{u}(\mathrm{k})}=0
\end{aligned}
$$

Form (1) and (9), the states and co-states are obtained as

$$
\left[\begin{array}{c}
\mathrm{x}_{\mathrm{j}}(\mathrm{k}+1) \\
\mathrm{p}_{\mathrm{j}}(\mathrm{k})
\end{array}\right]=\mathrm{C}\left[\begin{array}{c}
\varepsilon_{0} \ldots \varepsilon_{\mathrm{j}} \mathrm{x}_{\mathrm{j}}(\mathrm{k}) \\
\varepsilon_{0} \ldots \varepsilon_{\mathrm{j}} \mathrm{p}_{\mathrm{j}}(\mathrm{k}+1)
\end{array}\right]
$$

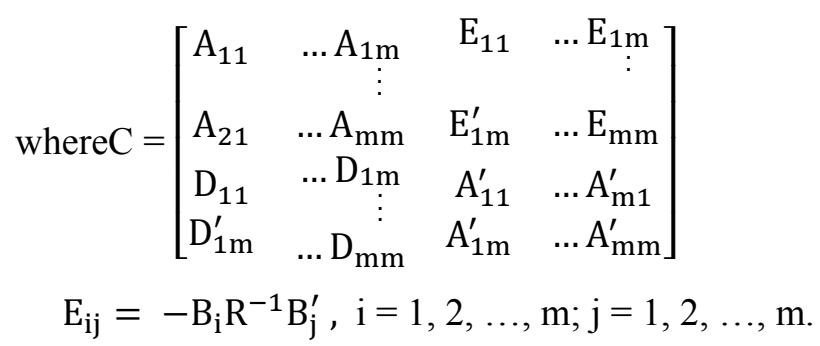

The final conditions of the system (10a) are

$$
p_{i}(N)=0, i=0,1, \ldots, n .
$$

The optimal control is obtained as

$$
\begin{gathered}
\mathrm{u}^{\mathrm{q}}(\mathrm{k})=-\mathrm{R}^{-1} \sum_{\mathrm{j}=0}^{\mathrm{n}}\left[\mathrm{B}_{\mathrm{j}+1}^{\prime} \varepsilon_{0} \varepsilon_{1} \ldots \varepsilon_{\mathrm{j}} \mathrm{p}_{\mathrm{j}}^{\mathrm{q}-\mathrm{j}}(\mathrm{k}+1)\right], \\
\mathrm{j}=0,1, \ldots, \mathrm{n} .
\end{gathered}
$$

The set of equations (10) constitutes the open-loop optimal control problem. The $2\left(\mathrm{n}_{1}+\mathrm{n}_{2}+\ldots+\mathrm{n}_{\mathrm{m}}\right)$ th order discrete TPBVP represented by (10) is in the singularly perturbed form in the sense that the degenerate TPBVP

$\left[\begin{array}{c}x_{0}^{0 \ldots 0}(k+1) \\ x_{j}^{0 \ldots 0}(k+1) \\ p_{0}^{0 \ldots 0}(k) \\ p_{j}^{0 \ldots 0}(k)\end{array}\right]=C\left[\begin{array}{c}x_{0}^{0 \ldots 0}(k) \\ 0 \\ p_{0}^{0 \ldots 0}(k+1) \\ 0\end{array}\right], j=1,2, \ldots, n$.

obtained by suppressing the small parameters $\varepsilon_{1}, \varepsilon_{2}, \ldots, \varepsilon_{\mathrm{n}}$ in (10a) is of order $2 \mathrm{n} 1$ and can satisfy the boundary conditions

$\mathrm{x}_{0}^{00 \ldots 0}(\mathrm{k}=0)=\mathrm{x}_{0}(0)$ and $\mathrm{p}_{0}^{00 \ldots 0}(\mathrm{k}=\mathrm{N})=\mathrm{p}_{0}(\mathrm{~N})$ 
The other boundary conditions, in general, are $\mathrm{x}_{\mathrm{j}}^{00 \ldots 0}(\mathrm{k}=0) \neq \mathrm{x}_{\mathrm{j}}(0)$ and $\mathrm{p}_{\mathrm{j}}^{00 \ldots 0}(\mathrm{k}=\mathrm{N}) \neq \mathrm{p}_{\mathrm{j}}(\mathrm{N})$,

$$
\mathrm{j}=1,2, \ldots, \mathrm{n} \text {. }
$$

That is the boundary conditions $\mathrm{x}_{1}(0), \ldots, \mathrm{x}_{\mathrm{n}}(0)$ and $\mathrm{p}_{1}(\mathrm{~N}), \ldots, \mathrm{p}_{\mathrm{n}}(\mathrm{N})$ are lost in the process of degeneration and the loss of these boundary conditions contributes to the existence of boundary layers at initial and terminal points. The $2(\mathrm{n} 2+\ldots+\mathrm{nm})$ boundary conditions lost in the process of degeneration are recovered by the following singular method which gives an approximate solution to the stiff TPBVP represented by (10). Consequently it results in a suboptimal control.

\section{ii. Singular perturbation method of optimal control}

(a). Outer series

Let us assume asymptotic expansions for the outer solution in the small parameters as

$\left\{\mathrm{x}_{\mathrm{v}, \mathrm{o}}(\mathrm{k}), \mathrm{p}_{\mathrm{v}, \mathrm{o}}(\mathrm{k})\right\}=$

$\sum_{\mathrm{i}, \mathrm{j}, \ldots, \mathrm{r} \geq 0}^{\mathrm{q}}\left[\mathrm{x}_{\mathrm{v}}^{\mathrm{ij} \ldots \mathrm{r}}(\mathrm{k}), \mathrm{p}_{\mathrm{v}}^{\mathrm{ij} \ldots \mathrm{r}}(\mathrm{k})\right] \varepsilon_{1}^{\mathrm{i}} \varepsilon_{2}^{\mathrm{j}} \ldots \varepsilon_{\mathrm{n}}^{\mathrm{r}} ; \mathrm{v}=0,1, \ldots, \mathrm{n}$.

where $\mathrm{q}$ is the desired order of approximation. Substituting (14) in (10a) and equating like powers of the small parameter a set of equations may be obtained. The zero-order equation is the same as that given by (11). The following equations may be obtained for $\mathrm{n} \geq 3$.

\section{(b). Initial and terminal boundary-layer correction} series

Transformations:

In order to recover the boundary conditions lost in the process of degeneration and to provide the necessary data for solving the outer and BLC equations, we introduce the following transformations corresponding to the $2 \mathrm{n}$ boundary layer corrections ( $\mathrm{n}$ initial and $\mathrm{n}$ terminal) that give unique solution as

Transformations for Initial BLC:

$$
\begin{aligned}
& \mathrm{x}_{0 \text { ci }}(\mathrm{k})=\mathrm{x}_{0}(\mathrm{k}) /\left(\varepsilon_{1} \ldots \varepsilon_{\mathrm{i}}\right)^{\mathrm{k}+1}, \mathrm{i}=1,2, \ldots, \mathrm{n} \text {. } \\
& \mathrm{x}_{1 \mathrm{c} 1}(\mathrm{k})=\mathrm{x}_{1}(\mathrm{k}) /\left(\varepsilon_{1}\right)^{\mathrm{k}} \\
& \mathrm{x}_{1 \mathrm{ci}}(\mathrm{k})=\mathrm{x}_{1}(\mathrm{k}) /\left(\varepsilon_{1}^{\mathrm{k}}\left(\varepsilon_{2} \ldots \varepsilon_{\mathrm{i}}\right)^{\mathrm{k}+1}\right), \mathrm{i}=2,3, \ldots, \mathrm{n} \text {. } \\
& \mathrm{x}_{2 \mathrm{ci}}(\mathrm{k})=\mathrm{x}_{2}(\mathrm{k}) /\left(\varepsilon_{1} \ldots \varepsilon_{\mathrm{i}}\right)^{\mathrm{k}}, \mathrm{i}=1,2 \text {. } \\
& \mathrm{x}_{2 \mathrm{ci}}(\mathrm{k})=\mathrm{x}_{2}(\mathrm{k}) /\left(\left(\varepsilon_{1} \varepsilon_{2}\right)^{\mathrm{k}}\left(\varepsilon_{3} \ldots \varepsilon_{\mathrm{i}}\right)^{\mathrm{k}+1}\right) \text {, } \\
& \mathrm{i}=3,4, \ldots, \mathrm{n} \text {. } \\
& \ddot{x}_{n c i}(k)=x_{n}(k) /\left(\varepsilon_{1} \ldots \varepsilon_{i}\right)^{k}, i=1,2, \ldots, n . \\
& \mathrm{x}_{\mathrm{jti}}(\mathrm{k})=\mathrm{x}_{\mathrm{j}}(\mathrm{k}) /\left(\varepsilon_{1} \ldots \varepsilon_{\mathrm{i}}\right)^{\mathrm{N}-\mathrm{k}+1}, \mathrm{j}=0,1,2, \ldots, \mathrm{n} \text {; } \\
& \mathrm{i}=1,2, \ldots, \mathrm{n} \text {. }
\end{aligned}
$$

Transformations for Terminal BLC:

$$
\mathrm{p}_{\mathrm{jci}}(\mathrm{k})=\frac{\mathrm{p}_{\mathrm{j}}(\mathrm{k})}{\left(\varepsilon_{1} \ldots \varepsilon_{\mathrm{i}}\right)^{\mathrm{k}+1}}, \mathrm{i}=1,2, \ldots, \mathrm{n} ; \mathrm{j}=1,2, \ldots, \mathrm{n} \text {. }
$$

$$
\begin{aligned}
& \mathrm{p}_{0 \mathrm{ti}}(\mathrm{k})=\mathrm{p}_{0}(\mathrm{k}) /\left(\varepsilon_{1} \ldots \varepsilon_{\mathrm{i}}\right)^{\mathrm{N}-\mathrm{k}+1}, \mathrm{i}=1,2, \ldots, \mathrm{n} . \\
& \mathrm{p}_{1 \mathrm{t} 1}(\mathrm{k})=\mathrm{p}_{1}(\mathrm{k}) /\left(\varepsilon_{1}\right)^{\mathrm{N}-\mathrm{k}} . \\
& \mathrm{p}_{1 \mathrm{ti}}(\mathrm{k})=\mathrm{p}_{1}(\mathrm{k}) /\left(\varepsilon_{1}^{\mathrm{N}-\mathrm{k}}\left(\varepsilon_{2} \ldots \varepsilon_{\mathrm{i}}\right)^{\mathrm{N}-\mathrm{k}+1}\right), \mathrm{i}=1,2, \ldots, \mathrm{n} . \\
& \mathrm{p}_{2 \mathrm{ti}}(\mathrm{k})=\mathrm{p}_{2}(\mathrm{k}) /\left(\varepsilon_{1} \ldots \varepsilon_{\mathrm{i}}\right)^{\mathrm{N}-\mathrm{k}}, \mathrm{i}=1,2 . \\
& \mathrm{p}_{2 \mathrm{ti}}(\mathrm{k})=\mathrm{p}_{2}(\mathrm{k}) /\left(\left(\varepsilon_{1} \varepsilon_{2}\right)^{\mathrm{N}-\mathrm{k}}\left(\varepsilon_{3} \ldots \varepsilon_{\mathrm{i}}\right)^{\mathrm{N}-\mathrm{k}+1}\right), \\
& \mathrm{i}=3,4, \ldots, \mathrm{n} .
\end{aligned}
$$

$\cdots$

$\mathrm{p}_{\mathrm{nti}}(\mathrm{k})=\mathrm{p}_{\mathrm{n}}(\mathrm{k}) /\left(\varepsilon_{1} \ldots \varepsilon_{\mathrm{i}}\right)^{\mathrm{N}-\mathrm{k}}, \mathrm{i}=1,2, \ldots, \mathrm{n} . \quad(15 \mathrm{~b})$

Here suffixes $c$ and $t$ refer to initial and terminal boundary layer corrections respectively.

\section{(c). Total series solution}

For a desired order of approximation $\mathrm{q}$, the total series solution of states $\mathrm{x}(\mathrm{k})$ and co-states $\mathrm{p}(\mathrm{k})$ may be obtained from outer and BLC solutions as

$$
\begin{aligned}
& \left\{\mathrm{x}_{0}^{\mathrm{q}}(\mathrm{k}), \mathrm{p}_{0}^{\mathrm{q}}(\mathrm{k})\right\} \\
& =\sum_{\mathrm{i}, \mathrm{j}, \ldots, \mathrm{r} \geq 0}^{\mathrm{q}}\left\{\mathrm{x}_{0}^{\mathrm{ij} \ldots \mathrm{r}}(\mathrm{k}), \mathrm{p}_{0}^{\mathrm{ij} \ldots \mathrm{r}}(\mathrm{k})\right\} \varepsilon_{1}^{\mathrm{i}} \varepsilon_{2}^{\mathrm{j}} \ldots \varepsilon_{\mathrm{n}}^{\mathrm{r}} \\
& +\sum_{\mathrm{s}=1}^{\mathrm{n}}\left(\varepsilon_{1} \ldots \varepsilon_{\mathrm{s}}\right)^{\mathrm{k}+1} \\
& * \sum_{\mathrm{i}, \mathrm{j}, \ldots, \mathrm{r} \geq 0}^{\mathrm{q}}\left\{\mathrm{x}_{0 \mathrm{cs}}^{\mathrm{ij} \ldots \mathrm{r}}(\mathrm{k}), \mathrm{p}_{0 \mathrm{cs}}^{\mathrm{ij} \ldots \mathrm{r}}(\mathrm{k})\right\} \varepsilon_{1}^{\mathrm{i}} \varepsilon_{2}^{\mathrm{j}} \ldots \varepsilon_{\mathrm{n}}^{\mathrm{r}} \\
& +\sum_{\mathrm{v}=1}^{\mathrm{n}}\left(\varepsilon_{1} \ldots \varepsilon_{\mathrm{v}}\right)^{\mathrm{N}-\mathrm{k}+1} \\
& * \sum_{\mathrm{i}, \mathrm{j}, \ldots, \mathrm{r} \geq 0}^{\mathrm{q}}\left\{\mathrm{x}_{0 \mathrm{tv}}^{\mathrm{ij} \ldots \mathrm{r}}(\mathrm{k}), \mathrm{p}_{0 \mathrm{tv}}^{\mathrm{ij} \ldots \mathrm{r}}(\mathrm{k})\right\} \varepsilon_{1}^{\mathrm{i}} \varepsilon_{2}^{\mathrm{j}} \ldots \varepsilon_{\mathrm{n}}^{\mathrm{r}}
\end{aligned}
$$

$$
\begin{aligned}
& \mathrm{x}_{\mathrm{f}}^{\mathrm{q}}(\mathrm{k}) \sum_{\mathrm{i}, \mathrm{j}, \ldots, \mathrm{r} \geq 0}^{\mathrm{q}} \mathrm{x}_{\mathrm{f}}^{\mathrm{ij} \ldots \mathrm{r}}(\mathrm{k}) \varepsilon_{1}^{\mathrm{i}} \varepsilon_{2}^{\mathrm{j}} \ldots \varepsilon_{\mathrm{n}}^{\mathrm{r}} \\
& +\sum_{\mathrm{s}=1}^{\mathrm{f}}\left(\varepsilon_{1} \ldots \varepsilon_{\mathrm{s}}\right)^{\mathrm{k}} \sum_{\mathrm{i}, \mathrm{j}, \ldots, \mathrm{r} \geq 0}^{\mathrm{q}} \mathrm{x}_{\mathrm{fcs}}^{\mathrm{ij} \ldots \mathrm{r}}(\mathrm{k}) \varepsilon_{1}^{\mathrm{i}} \varepsilon_{2}^{\mathrm{j}} \ldots \varepsilon_{\mathrm{n}}^{\mathrm{r}}+
\end{aligned}
$$$$
\sum_{\mathrm{s}=\mathrm{f}+1}^{\mathrm{n}}\left(\varepsilon_{1} \ldots \varepsilon_{\mathrm{f}}\right)^{\mathrm{k}}\left(\varepsilon_{\mathrm{f}+1} \ldots \varepsilon_{\mathrm{s}}\right)^{\mathrm{k}+1} *
$$$$
\sum_{\mathrm{i}, \mathrm{j}, \ldots, \mathrm{r} \geq 0}^{\mathrm{q}} \mathrm{x}_{\mathrm{fcs}}^{\mathrm{ij} \ldots \mathrm{r}}(\mathrm{k}) \varepsilon_{1}^{\mathrm{i}} \varepsilon_{2}^{\mathrm{j}} \ldots \varepsilon_{\mathrm{n}}^{\mathrm{r}}+
$$$$
\sum_{\mathrm{v}=1}^{\mathrm{n}}\left(\varepsilon_{1} \ldots \varepsilon_{\mathrm{v}}\right)^{\mathrm{N}-\mathrm{k}+1} \sum_{\mathrm{i}, \mathrm{j}, \ldots, \mathrm{r} \geq 0}^{\mathrm{q}} \mathrm{x}_{\mathrm{ftv}}^{\mathrm{ij} \ldots \mathrm{r}}(\mathrm{k}) \varepsilon_{1}^{\mathrm{i}} \varepsilon_{2}^{\mathrm{j}} \ldots \varepsilon_{\mathrm{n}}^{\mathrm{r}}
$$

$$
\mathrm{f}=1,2, \ldots, \mathrm{n} .
$$




$$
\begin{aligned}
& \mathrm{p}_{\mathrm{f}}^{\mathrm{q}}(\mathrm{k}){ }^{\mathrm{q}} \sum_{\mathrm{i}, \ldots, \mathrm{r} \geq 0} \mathrm{p}_{\mathrm{f}}^{\mathrm{ij} \ldots \mathrm{r}}(\mathrm{k}) \varepsilon_{1}^{\mathrm{i}} \varepsilon_{2}^{\mathrm{j}} \ldots \varepsilon_{\mathrm{n}}^{\mathrm{r}} \\
& +\sum_{\mathrm{s}=1}^{\mathrm{n}}\left(\varepsilon_{1} \ldots \varepsilon_{\mathrm{s}}\right)^{\mathrm{k}+1} \sum_{\mathrm{i}, \mathrm{j}, \ldots, \mathrm{r} \geq 0}^{\mathrm{q}} \mathrm{p}_{\mathrm{fcs}}^{\mathrm{ij} \ldots \mathrm{r}}(\mathrm{k}) \varepsilon_{1}^{\mathrm{i}} \varepsilon_{2}^{\mathrm{j}} \ldots \varepsilon_{\mathrm{n}}^{\mathrm{r}}+ \\
& \quad \sum_{\mathrm{v}=1}^{\mathrm{f}}\left(\varepsilon_{1} \ldots \varepsilon_{\mathrm{v}}\right)^{\mathrm{N}-\mathrm{k}} \sum_{\mathrm{i}, \mathrm{j}, \ldots, \mathrm{r} \geq 0}^{\mathrm{q}} \mathrm{p}_{\mathrm{ftv}}^{\mathrm{ij} \ldots \mathrm{r}}(\mathrm{k}) \varepsilon_{1}^{\mathrm{i}} \varepsilon_{2}^{\mathrm{j}} \ldots \varepsilon_{\mathrm{n}}^{\mathrm{r}} \\
& +\sum_{\mathrm{v}=\mathrm{f}+1}^{\mathrm{n}}\left(\varepsilon_{1} \ldots \varepsilon_{\mathrm{f}}\right)^{\mathrm{N}-\mathrm{k}}\left(\varepsilon_{\mathrm{f}+1} \ldots \varepsilon_{\mathrm{v}}\right)^{\mathrm{N}-\mathrm{k}+1} \\
& +\sum_{\mathrm{ij} \ldots \mathrm{r} \geq 0}^{\mathrm{q}} \mathrm{p}_{\mathrm{ftv}}^{\mathrm{ij} \ldots \mathrm{r}}(\mathrm{k}) \varepsilon_{1}^{\mathrm{i}} \varepsilon_{2}^{\mathrm{j}} \ldots \varepsilon_{\mathrm{n}}^{\mathrm{r}}
\end{aligned}
$$

$$
\mathrm{f}=1,2, \ldots, \mathrm{n} \text {. }
$$

Here terms with negative power for singular perturbation parameters $\varepsilon_{\mathrm{i}}$ are defined to be zero, if any.Now the suboptimal control law $\mathrm{u}(\mathrm{k})$ may be computed using (16) as

$$
\mathrm{u}^{\mathrm{q}}(\mathrm{k})=-\mathrm{R}^{-1} \sum_{\mathrm{j}=0}^{\mathrm{n}}\left[\mathrm{B}_{\mathrm{j}+1}^{\prime} \quad \varepsilon_{0} \varepsilon_{1} \ldots \varepsilon_{\mathrm{j}} \mathrm{p}_{\mathrm{j}}^{\mathrm{q}-\mathrm{j}}(\mathrm{k}+1)\right]
$$

Here $\mathrm{q}$ is the desired order of approximation.

\section{(d). Boundary conditions}

The boundary conditions to solve outer equations (14) and BLC equations (15) are to be furnished a priori. These are fixed uniquely from the fact that the total series solution (16) should satisfy the specified boundary conditions (10b). Consequently the following boundary conditions result[].

\section{(e). Algorithm}

Algorithm is similar to the SPM of a TPBVP of discrete control systems (Case 2 problem [21]) as the formulation of this optimal control problem results in TPBVP. For a particular order of approximate solution, first find the outer solution for states and co-states. Then add the BLC corresponding to the least singular transformation. Continue this process and finally add the BLC corresponding to the most singular transformation. Once a particular order of solution is obtained for states and co-states using (16), then obtain the corresponding suboptimal control using (17) and asymptotic correctness.

\section{Boost Converter Analysis}

The PFC boost converter shown in Fig. 1 can be modeled as a switched linear system.

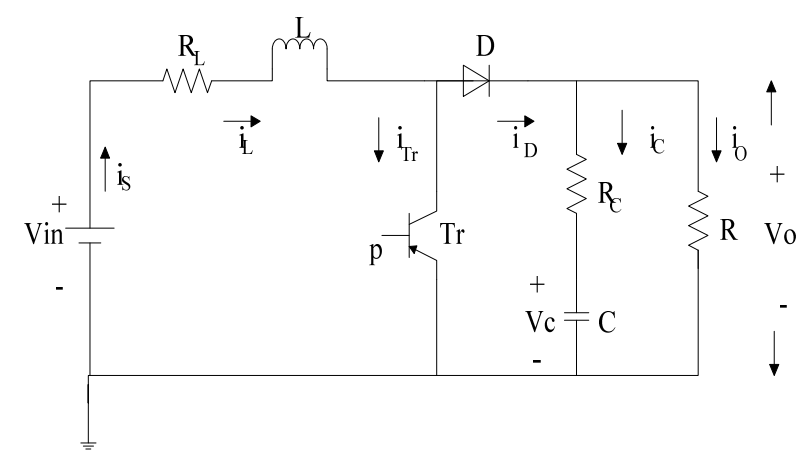

Fig. 1: Boost converter

The PFC application, implies large variation in input voltage and inductor current; otherwise, the dynamics are identical to any other boost converter. The switched linear model is

$\frac{d v_{C}}{d t}=-\frac{1}{C\left(R+R_{c}\right)} v_{C}+S_{d} \frac{1}{C\left(R+R_{c}\right)} i_{L}$

$\frac{\mathrm{di}_{\mathrm{L}}}{\mathrm{dt}}=-\mathrm{S}_{\mathrm{d}} \frac{\mathrm{R}}{\mathrm{L}\left(\mathrm{R}+\mathrm{R}_{\mathrm{c}}\right)} \mathrm{v}_{\mathrm{C}}-\frac{\mathrm{R}_{\mathrm{L}+} \mathrm{S}_{\mathrm{d}}\left(\mathrm{RR}_{\mathrm{L}} /\left(\mathrm{R}+\mathrm{R}_{\mathrm{L}}\right)\right)}{\mathrm{L}} \mathrm{i}_{\mathrm{L}}+\frac{\mathrm{v}_{\mathrm{in}}}{\mathrm{L}}$

Here, Sd is the switching function of the diode. All variables and coefficients must be normalized to put the system into standard form. The nominal output voltage is $V_{0}$, the nominal output current is $I_{0}=V_{0} / R$, and the switching period is T. With these definitions, the other variables can be normalized on the basis

$\varepsilon=\frac{\mathrm{L}}{\mathrm{CR}^{2}}$

$\mathrm{W}=\frac{\mathrm{V}_{\text {in }}}{\mathrm{V}_{\mathrm{o}}}$

$\delta=\frac{\mathrm{R}_{\mathrm{L}}}{\mathrm{R}} \frac{\left(\mathrm{R}+\mathrm{R}_{\mathrm{C}}\right)}{\mathrm{R}}$

$\mathrm{S}_{\mathrm{d}}=1-\mathrm{d}=\mathrm{u}$

$\hat{\mathrm{v}}_{\mathrm{C}}=\frac{\mathrm{v}_{\mathrm{C}}}{\mathrm{v}_{\mathrm{O}}}$

$\hat{\mathrm{i}}_{\mathrm{C}}=\frac{\mathrm{i}_{\mathrm{L}}}{\mathrm{i}_{\mathrm{O}}}$

$\mathrm{p}=\frac{\mathrm{T}}{\mathrm{C}\left(\mathrm{R}_{\mathrm{C}}+\mathrm{R}\right)}$

$\hat{\mathrm{t}}=\frac{\mathrm{T}}{\mathrm{C}\left(\mathrm{R}_{\mathrm{C}}+\mathrm{R}\right)}$

The first two variables are the normalized states. Normalized input voltage $\mathrm{w}$ is a disturbance input. The moving average of $S_{d}$, shown as $u$, is used as the input in the following analysis; often, the actual input is $d$, the duty cycle of the controlled switch. Then, the switching period $\mathrm{T}$ must be transformed into $\mathrm{p}$ on the $\hat{\mathrm{t}}$ timescale. The last two variables accumulate the various parameters of the physical system. The normalized switched dynamical system is

$$
\frac{\mathrm{d}}{\mathrm{dt}}\left[\begin{array}{c}
\hat{\mathrm{v}}_{\mathrm{C}} \\
\hat{\mathrm{l}}_{\mathrm{L}}
\end{array}\right]=\left[\begin{array}{cc}
-1 & \mathrm{~S}_{\mathrm{d}} \\
-\frac{\mathrm{S}_{\mathrm{d}}}{\varepsilon} & -\frac{\delta+\mathrm{S}_{\mathrm{d}} \frac{\mathrm{R}_{\mathrm{C}}}{\varepsilon}}{\varepsilon}
\end{array}\right]\left[\begin{array}{c}
\hat{\mathrm{v}}_{\mathrm{C}} \\
\hat{\mathrm{i}}_{\mathrm{L}}
\end{array}\right]+\left[\begin{array}{c}
0 \\
\frac{\mathrm{R}_{\mathrm{C}}+\mathrm{R}}{\varepsilon \mathrm{R}}
\end{array}\right] \mathrm{w}
$$


Averaging can be applied to (20) to enable further analysis. Although singular perturbation theory may be applied to time-varying systems, the switching power converter results are more readily applied if the system is first converted to an equivalent timeinvariant system. Since $\mathrm{Sd}$ is a switching function, the model (20) is linear in the states but time-varying. State-space averaging [37], which removes all knowledge of switching frequency, is typically used to form a nonlinear time-invariant converter model. Other averaging methods retain switching information in time-invariant models.

\section{Sample Data Discrete Analysis}

To study singular perturbation in digital controls, a sampled data model [30], [31] can be analyzed for timescale separation. Generic discrete-time systems have been analyzed with singular perturbation theory [32-36]. The boost converter of Fig. 1 demonstrates the basic problem of timescale separation with a digital control. First, the continuous-time model of (20) needs to be converted to discrete time. For notational convenience, rewrite the continuous-time model as

$\dot{\mathrm{x}}(\mathrm{t})=\mathrm{Fx}(\mathrm{t})+\mathrm{Gu}(\mathrm{t})$

Where $\mathrm{F}$ and $\mathrm{G}$ are respectively $\mathrm{m} \times \mathrm{m}$ and $\mathrm{m} \times \mathrm{p}$ real constant matrices with initial time is $t_{0}$ and sampling time is $\mathrm{t}$.

$\mathrm{x}(\mathrm{t})=\mathrm{e}^{\mathrm{F}(\mathrm{t}-\mathrm{t} 0)} \mathrm{x}\left(\mathrm{t}_{0}\right)+\int_{\mathrm{t}_{0}}^{\mathrm{t}} \mathrm{e}^{\mathrm{F}(\mathrm{t}-\tau)} \mathrm{Gu}(\tau) \mathrm{d} \tau$

In our case the input is sampled so we shall establish the solution going from one sampling instant $t_{0}=k T$ to the next sampling instant $\mathrm{t}=(\mathrm{k}+1) \mathrm{T}$.

$$
\begin{gathered}
\mathrm{x}(\mathrm{t})=\mathrm{e}^{\mathrm{F}(\mathrm{t}-\mathrm{kT})} \mathrm{x}(\mathrm{kT})+\int_{\mathrm{kT}}^{\mathrm{t}} \mathrm{e}^{\mathrm{F}(\mathrm{t}-\tau)} \mathrm{Gu}(\tau) \mathrm{d} \tau ; \\
\mathrm{kT} \leq \mathrm{t}<(k+1) T
\end{gathered}
$$

If we are interested in response at the sampling instants only, we set $\mathrm{t}=(\mathrm{k}+1) \mathrm{T}$. In response to $\mathrm{u}(\mathrm{k})$, the state settles to the value $\mathrm{x}(\mathrm{k}+1)$ prior to the application of input $\mathrm{u}(\mathrm{k}+1)$.

$$
\begin{gathered}
\mathrm{x}(\mathrm{k}+1)=\mathrm{A}[\mathrm{x}(\mathrm{k})]+\mathrm{B} \mathrm{u}(\mathrm{k}) \\
\text { where } \mathrm{A}=\mathrm{e}^{\mathrm{FT}} \\
\mathrm{B}=\int_{\mathrm{kT}}^{(\mathrm{k}+1) \mathrm{T}} \mathrm{e}^{\mathrm{F}((\mathrm{k}+1) \mathrm{T}-\tau)} \mathrm{G} \mathrm{d} \tau \\
\mathrm{B}=\int_{\mathrm{kT}}^{(\mathrm{k}+1) \mathrm{T}} \mathrm{e}^{\mathrm{F}((\mathrm{kT}+\mathrm{T}-\tau)} \mathrm{G} \mathrm{d} \tau
\end{gathered}
$$

Letting $\mu=(\tau-\mathrm{kT})$ in (24a), we have

$$
\mathrm{B}=\int_{0}^{\mathrm{T}} \mathrm{e}^{\mathrm{F}(\mathrm{T}-\mu)} \mathrm{G} \mathrm{d} \mu \text { with } \theta=\mathrm{T}-\mu
$$

We get

$$
\mathrm{B}=\int_{0}^{\mathrm{T}} \mathrm{e}^{\mathrm{F} \theta} \mathrm{G} \mathrm{d} \theta
$$

If we are interested in the value of $x(k)$ between sampling instants, we first solve for $\mathrm{x}(\mathrm{kT})$ any $\mathrm{k}$ using state above equation and then use (24) $\mathrm{x}(\mathrm{t})$ to determine $\mathrm{x}(\mathrm{t})$ for $\mathrm{kT} \leq \mathrm{t}<(\mathrm{k}+1) \mathrm{T}$.

Algorithm for evaluation of matrix series:

We evaluate A by a series in the form

$$
\begin{aligned}
& \mathrm{A}=\mathrm{e}^{\mathrm{FT}}= \mathrm{I}+\mathrm{FT}\left(\mathrm{I}+\frac{\mathrm{FT}}{2}\left\{\mathrm{I}+\frac{\mathrm{FT}}{3}\left[\mathrm{I}+\cdots+\frac{\mathrm{FT}}{\mathrm{N}-1}(\mathrm{I}+\right.\right.\right. \\
&\left.\left.\left.\left.\frac{\mathrm{FT}}{\mathrm{N}}\right)\right] \ldots\right\}\right)
\end{aligned}
$$

which has better numerical properties than the direct series of powers. The empirical relation giving the number of terms $\mathrm{N}$ is

$$
\mathrm{N}=\min \{3 \text { !! FT !! + 6, 100 }\}
$$

This relation assures that no more than 100 terms are included. The B integral in (24b) can be evaluated term by term to give

$$
\begin{aligned}
\mathrm{B} & =\sum_{\mathrm{N}=0}^{\infty} \frac{\mathrm{F}^{\mathrm{i}} \mathrm{T}^{\mathrm{i}+1}}{(\mathrm{i}+1) !} \mathrm{G} \\
\mathrm{B} & =\left(\mathrm{I}+\frac{\mathrm{FT}}{2 !}+\frac{\mathrm{F}^{2} \mathrm{~T}^{2}}{3 !}+\ldots\right) \mathrm{TG} \\
\mathrm{B} & =\left(\mathrm{e}^{\mathrm{FT}}-1\right) \mathrm{F}^{-1} \mathrm{G}
\end{aligned}
$$

The transition (26) is possible only for a nonsingular matrix F. For a singular F, we may evaluate B from (26a) by the approximation technique described above.

\section{Application to A PFC Converter}

PFC boost converters rely on timescale separation for effective operation. The boost converter parameter has $657 \mathrm{uH}$ of line inductance (L), $77 \mathrm{uF}$ of output capacitance (C), $584 \mathrm{~m}$ ohm of line resistance (RL), $381 \mathrm{~m}$ ohm of capacitor output resistance (RC), $100 \mathrm{ohm}$ of output resistance (R) and switches at $25 \mathrm{kHz}$. Switching period (Sampling time) $\mathrm{T}=0.7 \mathrm{msec}$ [37]. The resulting system is given by

$\left[\begin{array}{l}\mathrm{x}_{0}(\mathrm{k}+1) \\ \mathrm{x}_{1}(\mathrm{k}+1)\end{array}\right]=\left[\begin{array}{cc}0.9993 & 0.0002 \\ -0.2471 & 0.0538\end{array}\right]\left[\begin{array}{l}\mathrm{x}_{0}(\mathrm{k}) \\ \mathrm{x}_{1}(\mathrm{k})\end{array}\right]+\left[\begin{array}{c}0 \\ 3.9612\end{array}\right] \mathrm{u}(\mathrm{k})$

Here $\mathrm{x}_{0}$ slow state variable, $\mathrm{x}_{1}$ fast state variable and $\mathrm{u}(\mathrm{k})$ is unit step control function. The eigen spectrum of this system

$(0.9992,0.0539)$

clearly indicates two-time-scale nature with one slow mode and one fast mode. Hence it is represented as a one-parameter system as shown below.

$$
\left[\begin{array}{c}
\mathrm{x}_{0}(\mathrm{k}+1) \\
\mathrm{x}_{1}(\mathrm{k}+1)
\end{array}\right]=\left[\begin{array}{cc}
0.9993 & 0.002 \\
-0.2471 & 0.538
\end{array}\right]\left[\begin{array}{c}
\mathrm{x}_{0}(\mathrm{k}) \\
\varepsilon \mathrm{x}_{1}(\mathrm{k})
\end{array}\right]+\left[\begin{array}{c}
0 \\
3.9612
\end{array}\right] \mathrm{u}(\mathrm{k})
$$

where $\varepsilon=0.1$. 


\section{BVP:}

$\mathrm{x} 0(10)=2, \mathrm{x} 1(0)=1$, This is TPBVP as $\mathrm{x} 0$ is specified at $\mathrm{k}=10$ and $\mathrm{x} 1$ is specified at initial point $(\mathrm{k}=0)$.

The solutions for zero, first, second-order approximations are obtained and compared with the exact solution as shown in the Table I for BVP. From these tables we observe that

$>$ The degenerate solution, obtained by making $\varepsilon$ equal to zero in $(27 a)$, is unable to satisfy the initial conditions $\mathrm{x} 1(0)$.

$>$ The zero-order solution, obtained from (6), incorporates BLCs and hence it recovers the initial conditions $\mathrm{x} 1(0)$. Thereafter, i.e., $\mathrm{k} \geq$ 1 , it remains equal to the degenerate solution.

$>$ The first-order solution improves the zeroorder solution and is closer to the exact solution.

$>$ The second-order solution improves the firstorder solution and is much closer to the exact solution.

$>$ Boundary layer (region of rapid transition) is formed at $\mathrm{k}=0$ for $\mathrm{x} 1$ (the change from exact to degenerate solution is 1 to -0.4980 .

\section{Optimal Problem:}

The initial conditions are given as

$\mathrm{x} 0(0)=1 ; \quad \mathrm{x} 1(0)=1$.

and the final conditions are

$\mathrm{p} 0(7)=0 ; \quad \mathrm{p} 1(7)=0$.

and the performance index

$\mathrm{J}=1 / 2 \sum_{\mathrm{k}=0}^{\mathrm{N}-1}\left[\mathrm{w}^{\prime}(\mathrm{k}) \mathrm{DW}(\mathrm{k})+\mathrm{u}^{\prime}(\mathrm{k}) \mathrm{Ru}(\mathrm{k})\right]$

where $\mathrm{R}=1, \mathrm{D}=\left[\begin{array}{ll}1 & 0 \\ 0 & 1\end{array}\right], \quad \mathrm{w}(\mathrm{k})=\left[\begin{array}{c}\mathrm{x}_{0}(\mathrm{k}) \\ \varepsilon \mathrm{x}_{1}(\mathrm{k})\end{array}\right]$

The singularly perturbed TPBVP of fourth-order corresponding to () is

$\left[\begin{array}{c}\mathrm{x}_{0}(\mathrm{k}+1) \\ \mathrm{x}_{1}(\mathrm{k}+1) \\ \mathrm{p}_{0}(\mathrm{k}) \\ \mathrm{p}_{1}(\mathrm{k})\end{array}\right]=$

$\left[\begin{array}{cccc}0.9993 & 0.002 & 0 & 0 \\ -0.2471 & 0.538 & 0 & -31.382 \\ 1 & 0 & 0.9993 & -2.4700 \\ 0 & 10 & 0.0002 & 0.5380\end{array}\right]\left[\begin{array}{c}\mathrm{x}_{0}(\mathrm{k}+1) \\ \varepsilon \mathrm{x}_{1}(\mathrm{k}+1) \\ \mathrm{p}_{0}(\mathrm{k}) \\ \varepsilon \mathrm{p}_{1}(\mathrm{k})\end{array}\right]$

Using the singular perturbation method developed in the previous section, the degenerate, zero, first and second-order solutions are evaluated and compared with the exact solution in Table III. Observations from this table are
$>$ The degenerate solution, obtained by making $\varepsilon$ equal to zero in (30), is unable to satisfy the boundary conditions of fast state and co-state specified as $\mathrm{x} 1(0)=1$ and $\mathrm{p} 1(7)=0$.

$>$ The zero-order solution, obtained from (16), incorporates BLCs and recovers these boundary conditions $\mathrm{x} 1(0)$ and $\mathrm{p} 1(7)$.

$>$ The first-order solution improves the zeroorder solution. The second-order solution improves the first-order solution and is much closer to the exact solution.

The exact solution of the fourth-order singularly perturbed discrete TPBVP given by (30) is obtained by the method of complementary functions suggested for continuous 'stiff' problems. This necessitates a numerical algorithm to be implemented on a digital computer. On the other hand, by using the present SPM, the various series solutions are easily obtained as the stiffness is removed and at the same time are very close to the exact solution. Thus it is seen that the singular perturbation method not only reduces the order but also removes the 'stiffness' of the problem. This can be evidenced from the eigenvalues of full and degenerate optimal control systems.

Eigenvalues of full optimal control system

$=\{151.1324 ; \quad 0.9993 ; \quad 1.0007 ; 0.0066\}$

Eigenvalues of degenerate optimal control system

$=\{1.0007 ; 0.9993\}$ 
Table I: Comparison of various series solutions with the exact solution for BVP

\begin{tabular}{|c|c|c|c|c|c|}
\hline $\mathrm{x}(\mathrm{k})$ & $\begin{array}{c}\text { Degenerate } \\
\text { Solution }\end{array}$ & $\begin{array}{c}\text { Zero } \\
\text { Order } \\
\text { Solution }\end{array}$ & $\begin{array}{c}\text { First } \\
\text { Order } \\
\text { Solution }\end{array}$ & $\begin{array}{c}\text { Second } \\
\text { Order } \\
\text { Solution }\end{array}$ & $\begin{array}{c}\text { Exact } \\
\text { Solution }\end{array}$ \\
\hline $\mathrm{x} 1(0)$ & 2.0141 & 2.0141 & 2.0134 & 2.0104 & 2.0073 \\
$\mathrm{x} 2(0)$ & -0.4980 & 1.0000 & 1.0000 & 1.0000 & 1.0000 \\
\hline $\mathrm{x} 1(1)$ & 2.0126 & 2.0126 & 2.0120 & 2.0097 & 2.0061 \\
$\mathrm{x} 2(1)$ & 3.4635 & 3.4635 & 3.4691 & 3.4936 & 3.5190 \\
\hline $\mathrm{x} 1(2)$ & 2.0112 & 2.0112 & 2.0107 & 2.0082 & 2.0054 \\
$\mathrm{x} 2(2)$ & 3.4639 & 3.4639 & 3.4827 & 3.5927 & 3.6548 \\
\hline $\mathrm{x} 1(3)$ & 2.0098 & 2.0098 & 2.0093 & 2.0075 & 2.0047 \\
$\mathrm{x} 2(3)$ & 3.4642 & 3.4642 & 3.4830 & 3.5931 & 3.6623 \\
\hline $\mathrm{x} 1(4)$ & 2.0084 & 2.0084 & 2.0080 & 2.0063 & 2.0040 \\
$\mathrm{x} 2(4)$ & 3.4646 & 3.4646 & 3.4833 & 3.5934 & 3.6629 \\
\hline $\mathrm{x} 1(5)$ & 2.0070 & 2.0070 & 2.0067 & 2.0051 & 2.0033 \\
$\mathrm{x} 2(5)$ & 3.4649 & 3.4649 & 3.4837 & 3.5938 & 3.6631 \\
\hline $\mathrm{x} 1(6)$ & 2.0056 & 2.0056 & 2.0053 & 2.0047 & 2.0027 \\
$\mathrm{x} 2(6)$ & 3.4653 & 3.4653 & 3.4840 & 3.5941 & 3.6632 \\
\hline $\mathrm{x} 1(7)$ & 2.0042 & 2.0042 & 2.0040 & 2.0034 & 2.0020 \\
$\mathrm{x} 2(7)$ & 3.4656 & 3.4656 & 3.4843 & 3.5944 & 3.6634 \\
\hline $\mathrm{x} 1(8)$ & 2.0028 & 2.0028 & 2.0027 & 2.0021 & 2.0013 \\
$\mathrm{x} 2(8)$ & 3.4660 & 3.4660 & 3.4847 & 3.5948 & 3.6636 \\
\hline $\mathrm{x} 1(9)$ & 2.0014 & 2.0014 & 2.0013 & 2.0009 & 2.0007 \\
\hline & 3.4663 & 3.4663 & 3.4850 & 3.5951 & 3.6638 \\
\hline & 2.0000 & 2.0000 & 2.0000 & 2.0000 & 2.0000 \\
\hline & 3.4667 & 3.4667 & 3.4853 & 3.5954 & 3.6639 \\
\hline
\end{tabular}


Table II: Comparison of various series solutions with the optimal solution for optimal

\begin{tabular}{|c|c|c|c|c|c|}
\hline $\mathrm{x}(\mathrm{k})$ & $\begin{array}{l}\text { Degenerate } \\
\text { Solution }\end{array}$ & $\begin{array}{c}\text { Zero Order } \\
\text { Solution }\end{array}$ & $\begin{array}{l}\text { First Order } \\
\text { Solution }\end{array}$ & $\begin{array}{c}\text { Second } \\
\text { Order } \\
\text { Solution }\end{array}$ & $\begin{array}{c}\text { Exact } \\
\text { Solution }\end{array}$ \\
\hline $\mathrm{x} 1(0)$ & 1.0000 & 1.0000 & 1.0000 & 1.0000 & 1.0000 \\
\hline $\mathrm{x} 2(0)$ & -0.2473 & 1.0000 & 1.0000 & 1.0000 & 1.0000 \\
\hline $\mathrm{p} 1(0)$ & 6.9707 & 6.9707 & 6.9732 & 6.9766 & 6.9797 \\
\hline $\mathrm{p} 2(0)$ & 0.0012 & 0.0012 & 0.0959 & 0.1852 & 0.2009 \\
\hline $\mathrm{u}(0)$ & 0.0000 & 0.0000 & $-7.8892 \mathrm{e}-04$ & 0.0152 & 0.0227 \\
\hline $\mathrm{x} 1(1)$ & 0.9993 & 0.9993 & 0.9993 & 0.9993 & 0.9993 \\
\hline $\mathrm{x} 2(1)$ & -0.2471 & -0.2471 & -0.2126 & -0.1710 & -0.1465 \\
\hline $\mathrm{p} 1(1)$ & 5.9749 & 5.9749 & 5.9774 & 5.9801 & 5.9825 \\
\hline $\mathrm{p} 2(1)$ & $9.9581 \mathrm{e}-04$ & $9.9581 \mathrm{e}-04$ & -0.0192 & -0.0249 & -0.0286 \\
\hline $\mathrm{u}(1)$ & 0.0000 & 0.0000 & $-6.3114 \mathrm{e}-04$ & 0.0134 & 0.0239 \\
\hline $\mathrm{x} 1(2)$ & 0.9986 & 0.9986 & 0.9986 & 0.9986 & 0.9986 \\
\hline $\mathrm{x} 2(2)$ & -0.2469 & -0.2469 & -0.2119 & -0.1697 & -0.1536 \\
\hline $\mathrm{p} 1(2)$ & 4.9790 & 4.9790 & 4.9811 & 4.9738 & 4.9852 \\
\hline $\mathrm{p} 2(2)$ & $7.9665 \mathrm{e}-04$ & $7.9665 \mathrm{e}-04$ & -0.0169 & -0.0235 & -0.0302 \\
\hline $\mathrm{u}(2)$ & 0.0000 & 0.0000 & $-4.7335 \mathrm{e}-04$ & 0.0105 & 0.0241 \\
\hline $\mathrm{x} 1(3)$ & 0.9979 & 0.9979 & 0.9979 & 0.9979 & 0.9979 \\
\hline $\mathrm{x} 2(3)$ & -0.2468 & -0.2468 & -0.2112 & -0.1685 & -0.1531 \\
\hline $\mathrm{p} 1(3)$ & 3.9832 & 3.9832 & 3.9847 & 3.9863 & 3.9878 \\
\hline $\mathrm{p} 2(3)$ & $5.9748 \mathrm{e}-04$ & $5.9748 \mathrm{e}-04$ & -0.0132 & -0.0215 & -0.0304 \\
\hline $\mathrm{u}(3)$ & 0.0000 & 0.0000 & $-3.1557 \mathrm{e}-04$ & 0.0083 & 0.0242 \\
\hline $\mathrm{x} 1(4)$ & 0.9972 & 0.9972 & 0.9972 & 0.9972 & 0.9972 \\
\hline $\mathrm{x} 2(4)$ & -0.2466 & -0.2466 & -0.2099 & -0.1670 & -0.1526 \\
\hline $\mathrm{p} 1(4)$ & 2.9874 & 2.9874 & 2.9884 & 2.9895 & 2.9905 \\
\hline $\mathrm{p} 2(4)$ & $3.9832 \mathrm{e}-04$ & $3.9832 \mathrm{e}-04$ & -0.0105 & -0.0206 & -0.0305 \\
\hline $\mathrm{u}(4)$ & 0.0000 & 0.0000 & $-1.5778 \mathrm{e}-04$ & 0.0081 & 0.0242 \\
\hline
\end{tabular}




\begin{tabular}{|c|c|c|c|c|c|}
\hline $\mathrm{x} 1(5)$ & 0.9965 & 0.9965 & 0.9965 & 0.9965 & 0.9965 \\
$\mathrm{x} 2(5)$ & -0.2464 & -0.2464 & -0.2082 & -0.1659 & -0.1522 \\
$\mathrm{p} 1(5)$ & 1.9916 & 1.9916 & 1.9920 & 1.9927 & 1.9931 \\
$\mathrm{p} 2(5)$ & $1.9916 \mathrm{e}-04$ & $1.9916 \mathrm{e}-04$ & -0.0102 & -0.0191 & -0.0306 \\
$\mathrm{u}(5)$ & 0.0000 & 0.0000 & 0.0000 & 0.0073 & 0.0241 \\
\hline $\mathrm{x} 1(6)$ & 0.9958 & 0.9958 & 0.9958 & 0.9958 & 0.9958 \\
$\mathrm{x} 2(6)$ & -0.2462 & -0.2462 & -0.2079 & -0.1620 & -0.1524 \\
$\mathrm{p} 1(6)$ & 0.9958 & 0.9958 & 0.9958 & 0.9958 & 0.9958 \\
$\mathrm{p} 2(6)$ & 0.0000 & 0.0000 & -0.0092 & -0.0189 & -0.0304 \\
$\mathrm{u}(6)$ & 0.0000 & 0.0000 & $1.2676 \mathrm{e}-04$ & 0.0000 & 0.0000 \\
\hline $\mathrm{x} 1(7)$ & 0.9951 & 0.9951 & 0.9951 & 0.9951 & 0.9951 \\
$\mathrm{x} 2(7)$ & -0.2461 & -0.2461 & -0.2555 & -0.2689 & -0.2703 \\
$\mathrm{p} 1(7)$ & 0.0000 & 0.0000 & 0.0000 & 0.0000 & 0.0000 \\
$\mathrm{p} 2(7)$ & -0.00016 & 0.0000 & 0.0000 & 0.0000 & 0.0000 \\
\hline
\end{tabular}

Table III. Comparison of PI for Approximate and Optimal Solutions

\begin{tabular}{|c|c|c|}
\hline S. No & Description of Solution & Performance Index \\
\hline 1 & Exact (Optimal) & 8.0046 \\
\hline 2 & Second order solution & 8.0048 \\
\hline 3 & First order solution & 8.0070 \\
\hline 4 & Zero order solution & 8.0089 \\
\hline 5 & Degenerate solution & 7.9901 \\
\hline
\end{tabular}

\section{Conclusion}

Time-scale separation is important in many applications, from PFC to low-voltage $\mathrm{dc}-\mathrm{dc}$ converters. Separation criteria were derived for buck converter in both continuous-time and discrete-time formulations. The relationship among inductance, capacitance, and the inductor's parasitic resistance dominated the small parameters. An experimental boost converter, with both resistive and constantpower loads, demonstrated the effects of various design choices. A simulated PFC converter showed that extremely simple controllers can produce good line current waveforms if there is timescale separation. Designers may use these results in several ways. If a particular converter is already designed, then the control designer may check the criteria before choosing a particular control methodology. Alternatively, if a particular control scheme is desired, the power designer can make component choices that ensure separation. The separation criteria can also be used as constraints to improve a converter optimization problem. Future work will explore similar concepts for other converter topologies and closed-loop systems. Depending on component selection, there may be two timescale. In a closed- 
loop system, the input $u$ is no longer exogenous, but instead is a function of the states $\mathrm{x} 0$ and $\mathrm{x} 1$, and the disturbance input $u$. The feedback system may itself contain extra states, and may either enhance or detract from timescale separation. As shown in the example PFC controller, though, a controller built entirely on the slow timescale will usually be effective if there is timescale separation.

\section{Acknowledgements}

We greatly acknowledge Gudlavalleru Engineering College and Siddhartha Academy of General and Technical Education, Vijayawada for providing the facilities to carry out this research.

\section{References:}

[1] Anouar Bouazza. Comparison of singular perturbations approximation method and metaheuristic-based techniques for order reduction of linear discrete systems. Applied and Computational Mathematics 2017. Special Issue: Some Novel Algorithms for Global Optimization and Relevant Subjects; 6: 48-54.

[2] Adel Tellili, Nouceyba Abdelkrim. Diagnosis of discrete-time singularly perturbed systems based on slow subsystem. ACTA Mechanica Et Automatica 2014; 8: 175-180.

[3] Xin, H., Gan, D. ,Huang, M. and Wang, K. Estimating the stability region of singular perturbation power systems with saturation nonlinearities: an linear matrix inequality based method. Control Theory \& Applications, IET 2010; 4: $351-361$.

[4] Baolin Zhang and MingQu Fan. Near optimal control for singularly perturbed systems with small time-delay. Intelligent Control and Automation, WCICA 2008. 7th World Congress; $7212-7216$.

[5] Dmitriev M. and Kurina G. Singular perturbations in control problems. J Automation and Remote Control 2006; 67: 1-43.

[6] Naidu D. S. Singular perturbations and time scales in control theory and applications: An Overview. Dynamics of Continuous, Discrete \& Impulsive Systems 2002; 9: 233-278.

[7] Kevorkian J. K. and Cole J. D. Multiple scale and singular perturbation methods. Series: Applied mathematical science $s$ (SpringerVerlag, New York Inc.) 1996; 114.

[8] Saksena V. R., O'Reiley J. and Kokotovic P. V. Singular perturbations and time-scale methods in control theory: Survey 1976-1983. Automatica 1984; 20: 273-293.

[9] Yuan Yuan, Fuchun Sun and Yenan $\mathrm{Hu}$. Decentralized multi-objective robust control of interconnected fuzzy singular perturbed model with multiple perturbation parameters. In: 2012

IEEE International Conference on Fuzzy Systems. Brisbane, QLD, Australia: IEEE. pp. 18.

[10] Yong Chen and Yongqiang Liu. Summary of Singular perturbation modeling of multi-time scale power systems. In 2005 IEEE/PES Transmission \& Distribution Conference \& Exposition: Asia and Pa cific. Dalian, China: IEEE. pp. 1-4.

[11] Koichi F. and Kunihiko K. Bifurcation cascade as chaotic itinerancy with multiple time scales. Chaos: An Interdisciplinary J Nonlinear Science 2003; 13: 1041-1056.

[12] Krishnarayalu M. S. Singular perturbation methods for one-point, two-point and multipoint boundary value problems in multiparameter digital control systems. $J$ Electrical and Electronics Eng 1999; 19: 97110.

[13] Krishnarayalu M. S. Singular perturbation methods for a class of initial and boundary value problems in multi-parameter classical digital control systems. ANZIAM J 2004; Vol. 46: 6777.

[14] Krishnarayalu M. S. Singular perturbation method applied to the discrete Euler-Lagrange free-endpoint optimal control problem. Automatic Control (theory and applications) AMSE J 2008; 63:16-29.

[15] Krishnarayalu M. S. Singular perturbation methods for one-point, two-point and multipoint boundary value problems in multiparameter digital control systems. $J$ Electrical and Electronics Eng 1999; 19: 97110.

[16] Krishnarayalu M. S. Singular perturbation methods for a class of initial and boundary value problems in multi-parameter classical digital control systems. ANZIAM J 2004; Vol. 46: 6777.

[17] Krishnarayalu M. S. Singular perturbation method applied to the discrete Euler-Lagrange free-endpoint optimal control problem. Automatic Control (theory and applications) AMSE J 2008; 63:16-29.

[18] Kishore Babu G. and Krishnarayalu M. S. An application of discrete two parameter singular perturbation method. IJERT 2012; 1: 1-10.

[19] Kishore Babu G. and Krishnarayalu M. S. Some applications of discrete one parameter singular perturbation method. J Control Eng and Tech 2014; 4: 76-81.

[20] Kishore Babu G. and Krishnarayalu M. S. Application of singular perturbation method to 
two parameter discrete power system model. $J$ Control and Instrumentation Engineering 2017; 3: 1-13.

[21] Kishore Babu G. and Krishnarayalu M. S. Shooting methods for two-point boundary value problems of discrete control systems. Int $J$ Comput Appl 2015; 111: 16-20.

[22] Kishore Babu G. and Krishnarayalu M. S. "Suboptimal Control of Singularly Perturbed wo Parameter Discrete Control System" International Electrical Engineering Journal (IEEJ) Vol. 5 (2014) No.11, pp. 1594-1604, ISSN 2078-2365

[23] Kishore Babu G. and Krishnarayalu M. S. "Suboptimal Control of Singularly Perturbed Discrete Control System", International Electrical Engineering Journal (IEEJ) Vol. 5 (2014) No.5, pp. 1413-1419, ISSN 2078-2365

[24] Kishore Babu G. and Krishnarayalu M. S. (2015), 'Suboptimal control of singularly perturbed multi-parameter discrete control system' IEEE International conference on Power, Instrumentation, Control and Computing(PICC).

[25] Kishore Babu G. and Krishnarayalu M. S. (2018), "Singular Perturbation Method", Text book in LAMBERT Academic Publications; ISBN: 978-620-2-06889-5.

[26] Dongdong Zheng, Wen-Fang Xie. Identification and control for singularly perturbed systems using multitime-scale neural networks. IEEE $T$ on Neural Networks and Learning Systems 2017; 28: 321-333.

[27] Rajasekhar Ananthoju, A. P. Tiwari, and Madhu N. Belur. A Two-Time-Scale Approach for Discrete-Time Kalman Filter Design and Application to AHWR Flux Mapping. IEEE T on Nuclear Sci. 2016; 63: 359-370.

[28] P. V. Kokotovi'c, H. K. Khalil, and J. O'Reilly, Singular Perturbation Methods in Control: Analysis and Design. London, U.K.: Academic, 1986.

[29] O. Garc'ia, J. A. Cobos, R. Prieto, P. Alou, and J. Uceda, "Single phase power factor correction: A survey," IEEE Trans. Power Elect ron., vol. 18, no. 3, pp. 749-755, May 2003.

[30] G. C. Verghese, M. E. Elbuluk, and J. G. Kassakian, "A general approach to sampled-data modeling for power electronic circuits,"IEEE Trans. Power Electron., vol. PEL-1, no. 2, pp. 76-89, Apr.1986.

[31] A. R. Brown and R. D. Middlebrook, "Sampleddata modeling of switching regulators," in Proc. IEEE Power Electron. Spec. Conf., 1981 , pp. 349- 369 .
[32] R. G. Phillips, "Two-timescale discrete systems," M.S. thesis, Univ.Illinois, UrbanaChampaign, 1979.

[33] P. V. Kokotovi'c, “A Riccati equation for block-diagonalization of illconditioned systems," IEEE Trans. Autom. Control, vol. 20, no. 6, pp. 812-814, Dec. 1975.

[34] E. C. Bekir, "Singular perturbation methods for discrete time systems," in Proc. IEEE Conf. Decis. Control, 1985, vol. 24, pp. 86-94.

[35] F. Hoppensteadt and W. Miranker, "Multitime methods for systems of difference equations," Stud. Appl. Math., vol. 56, pp. 273-289, Jun. 1977.

[36] R. G. Phillips, "Reduced order modelling and control of two-timescale discrete systems," Int. J. Control, vol. 31, pp. 765-780, Apr. 1980.

[37] Jonathan W. Kimball, "Singular Perturbation Theory for DC-DC Converters and Application to PFC Converters". IEEE transactions on power electronics, DOI: 10.1109/TPEL.2008.2004272, 2008 